\title{
Tremors but no Youthquake: Measuring changes in the age and turnout gradients at the 2015 and 2017 British general elections
}

\author{
Christopher Prosser ${ }^{\mathrm{a}, *}$, Edward Fieldhouse ${ }^{\mathrm{a}}$, Jane Green ${ }^{\mathrm{b}}$, Jonathan Mellon ${ }^{\mathrm{a}}$, Geoffrey Evans ${ }^{\mathrm{b}}$ \\ ${ }^{\text {a }}$ University of Manchester, United Kingdom \\ ${ }^{\mathrm{b}}$ Nuffield College, Oxford, United Kingdom
}

\section{A R T I C L E I N F O}

\section{Keywords:}

Youthquake

UK general elections

Turnout

Elections

Survey methodology

\begin{abstract}
A B S T R A C T
In the aftermath of the 2017 UK General Election, some claimed that Labour performed unexpectedly well because of a surge in youth turnout. Polling estimates for the size of this 'youthquake' ranged from 12 to 21 points amongst 18-24 year olds. Using conventional and Bayesian statistical methods, we analyse British Election Study and British Social Attitudes random probability surveys and find no evidence of a shift in the relationship between age and turnout of this scale. Using the pooled BES and BSA reported turnout data with an informative prior that there was a modest increase in 18-24 turnout $(N\{6,3\})$, our $95 \%$ credible interval for that change is between 0.9 and 8.8 points. Even with a strong youthquake prior $(N\{15.5,3.5\})$, our data suggest that there is only a $4 \%$ probability that the change in turnout amongst 18-24 years olds was 12 points or higher.
\end{abstract}

The result of the 2017 UK General Election confounded expectations. At the start of the campaign, Labour trailed the Conservatives by as much as 21 points in opinion polls. Over the course of the campaign Labour surged in the polls. The result of the election was neck-and-neck, with Labour only 2.3 percentage points behind the Conservatives. ${ }^{1}$ Although still well short of being able to form a government in terms of seats, the change in Labour's electoral fortunes was dramatic. The 2017 election saw Labour's highest vote share since 2001 and the largest single election increase in their share since 1945.

In the wake of this surprise outcome, political analysts and commentators began to look for an explanation. One proposition quickly gained prominence: Jeremy Corbyn had mobilised previously disengaged young voters who turned out in droves. Some claimed that turnout amongst $18-24$ year olds was as high as $72 \% .^{2}$ To use the term that soon gained traction: there had been a 'youthquake'.

Initial evidence seemed to suggest that there was something to the youthquake claim. At the aggregate constituency level, turnout change between 2015 and 2017 was correlated with the number of young people in a constituency (Heath and Goodwin, 2017). Two polls released after the election suggested that youth turnout had risen dramatically. One suggested that 18-24 year old turnout went up by 12 points (Britton, 2017). Another suggested a larger increase of 16 percentage points (Ipsos MORI 2017). Amongst academics, Whiteley and Clarke (2017) reported a 19 point increase in 18-29 turnout, whilst Sloam and Ehsan (2017) reported an increase of 21 points amongst 18-24 year olds. ${ }^{3}$

In this paper we assess these claims using British Election Study (BES) and British Social Attitudes (BSA) survey data. Whilst it is clear that Labour increased its support amongst young voters (see appendix 1 ), we find no good evidence to support the claims made about a large increase in youth turnout. The lessons from our analysis are not just important for understanding the 2017 UK General Election, they have wider implications for the measurement of and interpretation of political behaviour.

\footnotetext{
* Corresponding author. University of Manchester, Manchester, M13 9PL, United Kingdom.

E-mail address: chris.prosser@manchester.ac.uk (C. Prosser).

${ }^{1}$ For a brief overview of the election, see Prosser (2018).

${ }^{2}$ A figure that was apparently plucked out of thin air, see Dahir (2017).

${ }^{3}$ Neither Britton, nor Whiteley and Clarke, say whether they are measuring turnout amongst registered voters or the voting eligible, or age, population. Since they make no mention of registration, it seems reasonable to assume they are talking about either the voting eligible or voting age populations. Sloam and Ehsan's 21 point figure comes from Ipsos MORI, who report two numbers-a 16 point rise amongst all resident 18-24 year olds, and a 21 point rise amongst registered 18-24 year olds. Sloam and Ehsan do not make clear why they prefer the more dramatic number and do not report the lower number, nor do they report that it is measured as a proportion of registered voters. Ipsos MORI themselves say 'we believe the first figure [turnout amongst all resident adults] is both more reliable and more meaningful'.
} 


\section{Assessing the case for youthquake}

It is important to emphasise that we are examining the question of turnout specifically. Youthquake may be a powerful rhetorical device, but as a social scientific concept, it is slippery. Originally, youthquake described the 'shock [2017 general election] result founded on an unexpected surge in youth turnout' (Sloam and Ehsan 2017, 5). Later formulations included changes in party support amongst young people (Whiteley and Clarke, 2017), and some proponents argued that a youthquake also encompassed different campaigning styles, the role of social media, the Labour party's policy proposals, and the subsequent reaction of the Conservatives to the election result (Ehsan et al., 2017). It is impossible to determine whether a youthquake so flexibly defined has taken place. ${ }^{4}$ We deal with 'youthquake' as it was originally formulated, and examine the question of whether there was a substantial rise in turnout amongst young people.

\subsection{Explanations for the relationship between age and turnout}

It is long established that voter turnout varies with age (Milbrath, 1965), a pattern has been attributed to life-cycle effects, in particular the accumulation of resources (Verba et al., 1995) and acquisition of adult roles and experience (Strate et al., 1989).

Other research suggests that voting is habit forming (Cutts et al., 2009). Because young voters are yet to acquire these habits, they are more sensitive to contextual factors, such as how close an election is likely to be (Fieldhouse et al., 2007).

These explanations do not obviously lead to an expectation of a sudden increase in youth turnout in the 2017 British general election. Life-cycle effects are unlikely to have shifted much over the two years between the elections of 2015 and 2017. The 2017 election was widely perceived to be less competitive than in 2015 , when a hung parliament was anticipated.

There are also more mechanical reasons to question a disproportionate rise in turnout amongst young people. Overall turnout increased by 1.5 million people in 2017 . Those aged $18-24$ make up $11 \%$ of the electorate-about 5.2 million people. If there was a 16 point increase in 18-24 year old turnout, this would mean that more than half of the total increase in turnout would have come from this group. ${ }^{5}$ A 19 point increase in turnout amongst $18-29$ year olds (18\% of the electorate) would be 1.6 million people, more than the total increase in turnout at the election. ${ }^{6}$ Such dramatic changes are not impossible, but claims of this scale should obviously be accompanied by compelling evidence.

\subsection{Pre and post-election polling evidence}

As far as we are aware, there were three claims of a surge in youth turnout based on pre and post-election polling: 1) an NME 'exit poll' that

\footnotetext{
${ }^{4}$ There has also been some conceptual stretching about who counts as 'young'. For example, some argued that the definition of 'young' be expanded to include those up to the age of 40 (Ehsan et al., 2017). We focus on the 18-24 or 18-29 definitions of 'youth' as originally used by those who claimed a turnout youthquake, but we report our results across the age distribution.

5 Moreover, even if this increase in turnout did occur, it would still leave most of Labour's success unexplained. Labour won 3.5 million more votes in 2017 than in 2015 . If $18-24$ year old turnout increased by 16 points, this would be roughly 800,000 extra voters. Even if every single one of these extra voters voted Labour this would only account for about one quarter of Labour's vote gains in 2017.

6 The wider the age band used, the less plausible large turnout changes seem. A 16 point rise amongst those aged $18-39$, for example, would be a turnout increase in this age range of about one million more voters than the total turnout increase. Without a (substantial) decrease in turnout amongst those 40 and older, the ceiling turnout change amongst 18-39 year olds would be about nine points.
}

claimed a 12 point rise in 18-24 year old turnout, 2) an Ipsos MORI estimate of a 16 point rise in 18-24 year old turnout, and 3) an estimate of a 19 point rise in 18-29 turnout from the Essex Continuous Monitoring Survey (CMS). We examine these polls in more detail in appendix 2 , but summarise our main concerns here.

The NME 'exit' poll was conducted using a research panel launched in 2016, which raises the obvious question of how it can compare 2017 turnout with what happened in 2015. It also cannot be an 'exit' poll as described, because such polls cannot be used to measure turnout. Exit polls necessarily exclude non-voters because they sample people as they exit polling stations after having voted.

The Ipsos MORI (2017) data is reweighted pre-election polling. Assigning turnout on the basis of pre-election turnout likelihood is far from straightforward. As we show in appendix 2, the relationship between reported turnout likelihood during an election campaign and reporting voting afterwards is not stable between elections, or over the course of different campaigns.

The CMS uses non-probability internet survey data which, in publicly available and comparable data, has reported turnout levels well above actual turnout levels $(90 \%+)$.

These concerns do not mean that the claims made about turnout using these data are necessarily wrong, but given the magnitude of those claims, it does suggest that other data is needed.

\subsection{Aggregate evidence}

Aggregate constituency data shows that the change in constituencylevel turnout between 2015 and 2017 is correlated with the number of young people in a constituency in the 2011 census. However, when we examine the aggregate data more closely (see appendix 3 ), we find that turnout change is less strongly correlated with the 18-24 bracket than any of the other four voter eligible age brackets and is most strongly correlated with an age bracket that cannot vote: children aged zero to four. Few people, it is safe to say, would argue that the increase in turnout in 2017 was due to a sudden surge in the number of British toddlers voting in elections. 2017 was not the 'toddlerquake' election. This analysis shows the dangers of making inferences about individual behaviour from aggregate data because of the 'ecological fallacy' problem (Robinson, 1950).

\subsection{Labour party analysis of the electoral register}

Cowley and Kavanagh (2018) reported that 'an internal Labour Party estimate, based on analysis of several million records from marked electoral registers... [found] an increase in the involvement of those aged 18-24, of about ten percentage points'. As we detail in appendix 4, analysis of the electoral registers in Britain is far from straightforward because they contain no demographic information. Even ignoring these issues, however, an analysis of the registers necessarily excludes those who are not registered. Taking registration levels into account, the Labour Party's analysis suggests a 6.6-point rise in turnout amongst eligible 18-24 year olds, just over half of the lowest claim made about the change in youth turnout on the basis of post-election polling data.

\subsection{Evidence from the UK Household Longitudinal Study}

The final piece of evidence was presented by Sturgis and Jennings (2019), who analysed data from Understanding Society (the UK Household Longitudinal Study). Sturgis and Jennings report a nine-point rise in turnout for 18-24 year olds between 2015 and 2017. We need to take this evidence particularly seriously. Understanding Society (University of Essex et al. 2017) is a rigorously conducted scientific survey that uses a gold-standard methodology to randomly sample and retain its respondents. However, one aspect of the Understanding Society data makes us cautious about taking this data as the final word about turnout change between 2015 and 2017, namely that it is panel data. 


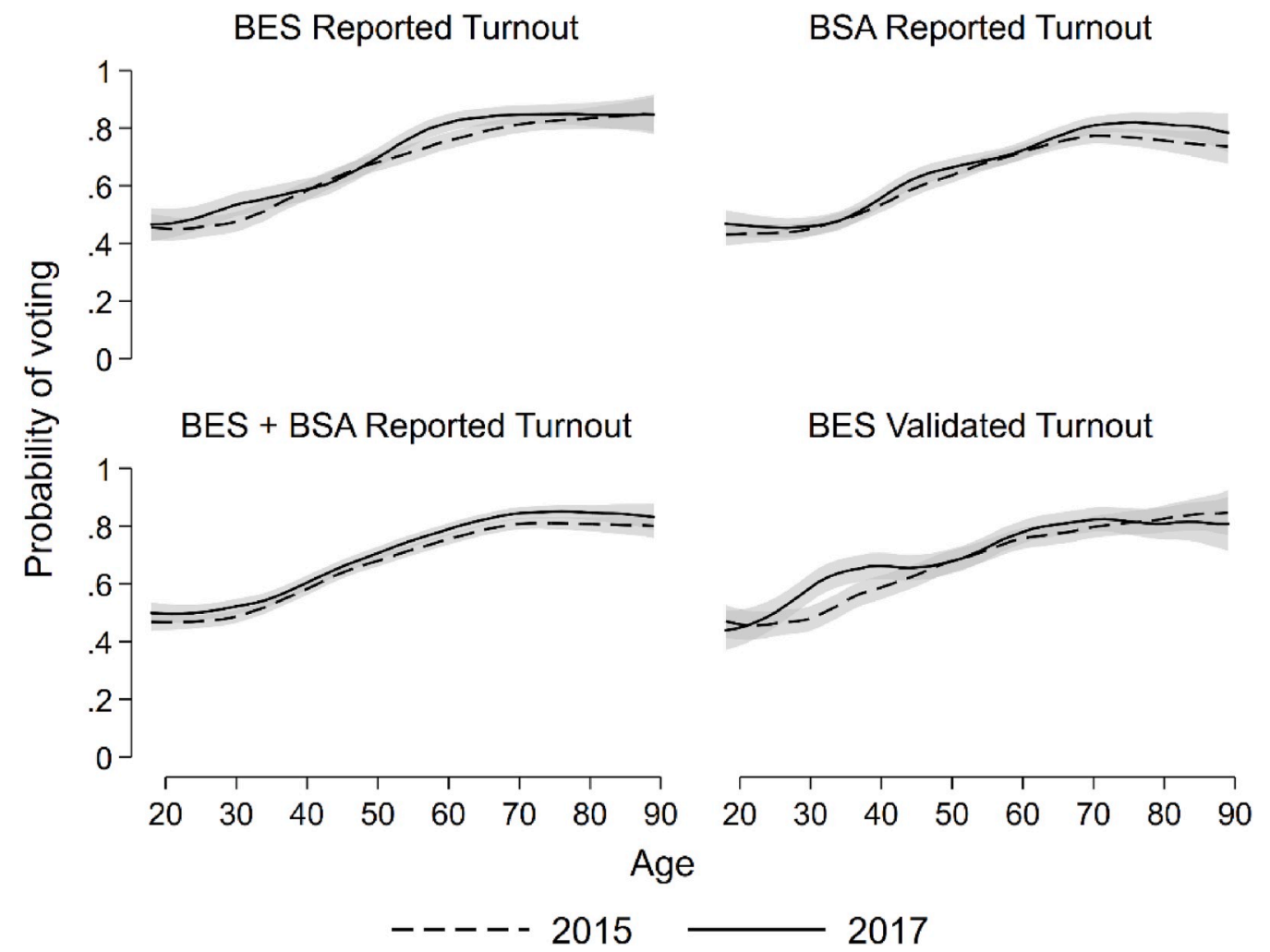

Fig. 1. Self-reported and validated nonparametric smoothed local mean turnout probability over age, bandwidth $=5$. The shaded areas show $95 \%$ confidence intervals.

Nonresponse bias with regards to turnout is a well-known problem with survey research and surveys are well known to overestimate turnout (e.g. Dahlgaard et al., 2019). In the first wave of Understanding Society, we would expect turnout nonresponse bias to be comparable to other random probability surveys. However, further nonresponse bias can occur in subsequent waves of panel surveys (attrition bias). ${ }^{7}$

If we examine whether a respondent who appeared in wave one of Understanding Society (conducted between 2009 and 2011) also appears in the 2015 turnout data, we see that a respondent who said they were very interested in politics in wave 1 is 12 percentage points more likely to appear in the 2015 data than a respondent who said they were not at all interested in politics. Understanding Society mitigates the effects of attrition by weighting, but even with weights, the gap between official turnout and that recorded in Understanding Society has grown over time: it was 9.1 points in 2010, 11.6 in 2015, and 12.4 in $2017 .^{8}$

Although attrition bias might be a problem for Understanding Society in general, it is an additional question whether this affects estimates of change in turnout amongst young people in particular. There are no population data about the demographics of turnout in the UK, so we cannot answer this question with absolute certainty. However, we can show that, even with minimal assumptions, it would be reasonable to

\footnotetext{
${ }^{7}$ An additional concern with panel data is that the simple fact of being in a panel survey might change how people behave, a problem known as panel conditioning (Sturgis et al., 2009). There is also some evidence that being asked about electoral participation specifically might increase the likelihood of voting (e.g. Greenwald et al., 1987). Because we do not observe the voting behaviour of non-respondents, we cannot assess the extent that these problems affect the Understanding Society data.

${ }^{8}$ For sake of comparison, the equivalent numbers for the BES were 7.3 in 2015 and 8.5 in 2017, and for the BSA they were 5.2 in 2015 and 4.6 in 2017. The fact that the overall level of turnout bias is lower in the BES and BSA data should also give us confidence that this data is our best chance of accurately assessing turnout in 2015 and 2017.
}

expect that attrition bias will particularly affect youth turnout estimates. In appendix 5 we report simulation results that show that if turnout tends to increase with age and attrition affected people of all ages equally, this would lead us to overestimate the level of turnout change amongst the youngest age groups. These are conservative assumptions given that we know that turnout does increase with age and young people are more likely to drop out of Understanding Society.

These concerns notwithstanding, it is important to note that Sturgis and Jennings's estimate is ten points lower than Whiteley and Clarke's, just over half the size of Ipsos MORI's, and three-quarters the size of NME's.

\section{Using survey data to measure turnout}

How, then, can we better assess claims made about changes to turnout in 2017? In the absence of official population register data- which we do not have in Britain-our only option is survey data.

Online and phone surveys are prone to representativeness problems, and tend to include too few non-voters in samples (Sturgis et al., 2017; Mellon and Prosser, 2017). The best way to minimise these problems is to use a random probability sample (Sturgis et al., 2017). As we discussed above, we are also likely to be on safer ground if we use cross-sectional surveys rather than panel surveys. We use the 2015 and 2017 editions of two such surveys: the BES face-to-face survey (Fieldhouse et al., 2015; 2017) and the BSA face-to-face survey (NatCen Social Research, 2017; 2019). Both are address-based random probability samples, such that respondents have a known chance of selection-in contrast to telephone and online opt-in samples.

Measuring turnout is still not straightforward. We need to overcome three challenges: 1) gathering accurate targets to adjust surveys for demographic imbalances due to differential response; 2) further adjusting surveys to account for the fact that, even with probability sampling and after accounting for demographic imbalances, people who turn out to vote are more likely to take part in surveys; and 3) dealing 


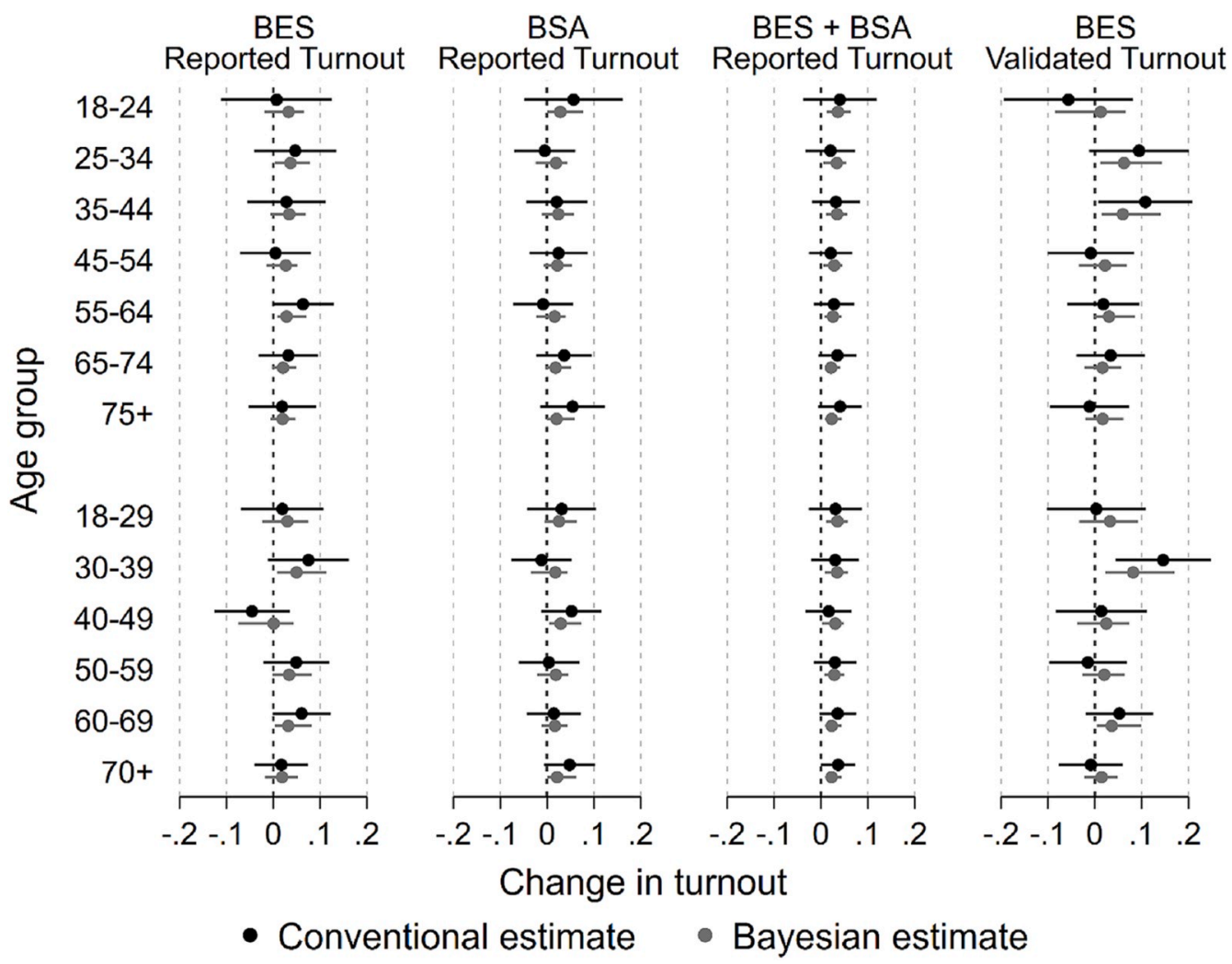

Fig. 2. Estimates of turnout change between 2015 and 2017, by age group.

with the fact that people over-report having voted in elections.

The methodology behind survey weighting is well established, but the BES data raises an additional challenge. The sampling frame for most surveys (including the BSA) is the resident adult population. The sampling frame for the BES is the resident voting eligible population (VEP). Weighting targets are generally available for the resident adult population, but in order to create VEP weights, we must estimate them. We describe our approach to doing this in appendix 6 .

Even after weighting, however, each survey has too many people who claim to have voted (relative to the actual level of turnout at the election). As we discussed above, this is likely due to two factors: one, turnout related nonresponse bias, and two, misreporting. We mitigate the impact of the first by weighting to the result of the relevant election in terms of turnout and party vote shares. As we show in appendix 7, although we only weight to overall levels of turnout, this weighting should also make our estimates of turnout in demographic subgroups more accurate.

To reduce the impact of misreporting, we make use of validated turnout in the BES. In order to validate whether or not a respondent had voted, their details were checked against the marked electoral register (see appendix 8 for more details). The vote validation process comes at a slight cost of sample size (and was not conducted for the BSA), and the process itself cannot be perfect.

We present our turnout analysis using self-reported and validated vote measures. The likely errors in these approaches work in the opposite direction: self-reported vote might overestimate turnout and validated vote might underestimate it. Where these two measures agree on the age/turnout relationship-and they generally do-we can be more confident in our findings.

\section{Age and turnout in 2015 and 2017}

We now turn to our analysis of turnout and age at the 2015 and 2017 elections. We conduct each set of analyses on four (overlapping) sets of data: on 1) BES reported vote, 2) BSA reported vote, 3) pooled BES and BSA reported vote data, treating the BSA data as if it were a Voter Eligible Population (VEP) sample, ${ }^{9}$ and 4) the BES validated vote data. ${ }^{10}$

\subsection{Nonparametric analysis}

First we analyse our data by plotting the nonparametric smoothed local mean (Fan and Gijbels, 1996) analysis of turnout by age, shown in Fig. 1. This method allows us to examine turnout without having to impose arbitrary cut-offs between age groups, or to impose a particular functional form on the relationship between age and turnout (i.e. it does not have to be linear or quadratic). Each set of comparisons tells the same story-the relationship between age and turnout was remarkably similar in 2015 and 2017. There is no evidence here of a substantial rise in turnout amongst young people. The validated turnout data suggests that turnout rose more substantially amongst $30-40$ year olds, but given the relatively small validated sample we should be cautious about this result, since we are more likely to observe large differences by chance in smaller samples (Gelman and Carlin 2014), and it is not corroborated by our other analysis.

\subsection{Pairwise comparison of age groups}

Next, we analyse turnout changes between 2015 and 2017 by

\footnotetext{
${ }^{9}$ Because VEP turnout change is necessarily greater than VAP turnout change, this slightly biases the BSA data towards a larger overall change in turnout. Given that our results are very similar between the separate BES and BES data when weighted appropriately and when they are pooled together, we do not think this bias has unduly influenced our conclusions.

${ }^{10}$ We additionally conducted a series of logistic regression models examining changes to the overall age/turnout gradient between elections. This analysis corroborates our other analysis, but for reasons of space we report these in appendix 9.
} 
categorising respondents into age groups. We use two sets of age groups, the first with the youngest age band of 18-24, and the second with a wider band of 18-29. We report the sample sizes for each comparison in appendix 10. Given concerns about the statistical power of relatively small samples, we also conduct a series of power analyses. We report the full results of these comparisons in appendix 10, but highlight some key comparisons here.

If we take the lowest youthquake claim of a 12 point increase as our benchmark (we will necessarily have more statistical power to reject the null hypothesis of no turnout increase if the true change is larger), using the 18-24 age band, the BES reported turnout data has 0.62 power, the BSA data 0.68 , the pooled BES and BSA data 0.92 , and the BES validated vote data 0.49 . Using the $18-29$ age band, the equivalent numbers are $0.88,0.95,0.99$, and 0.73 . Although some of the specific comparisons are underpowered, we can be reasonably confident that our pooled BES and BSA data are sufficiently powered to detect the smallest claim about a turnout youthquake. Even the data with the least power here-the BES validated vote data-is sufficiently powered to detect some of the larger claims about the turnout increase. For example, the BES validated vote data has 0.98 power if Whiteley and Clarke's claimed 19 point rise amongst 18-29 year olds were correct.

We compare turnout in 2015 and 2017 using two approaches. First, we use a conventional statistical approach to calculate confidence intervals around our observed differences in turnout. Second, we use a hierarchical Bayesian approach (with a logistic link function) to partially pool our results within age groups across elections, and across age groups within elections, and within age groups at each election, using the BRMS package (Bürkner, 2017), which compiles the model using Stan (Stan Development Team, 2018). The Bayesian approach allows us to incorporate information we can be more certain about-namely the overall level of turnout at each election-by specifying informative priors for the overall intercept and turnout increase in 2017. ${ }^{11}$ We report these comparisons in Fig. 2.

First, we examine our conventional estimates. For the 18-24 and 18-29 age groupings, across all four sets of data, the confidence intervals overlap zero. In other words, we cannot reject the null hypothesis that there was no change in the levels of turnout amongst young voters between 2015 and 2017. The absence of sufficient evidence to reject the null hypothesis is not the same thing as evidence in favour of the null. The confidence intervals in all of our comparisons are fairly wide and compatible with a wide range of changes in turnout-from a moderate increase to a small decrease (or even a large decrease in the case of the validated vote, but the other data suggest that this is unlikely to be the case).

As well as the null hypothesis, we can also examine whether our data are compatible with the youthquake hypothesis. If we test the smallest (and therefore, most difficult to reject) youthquake claim about turnout change - a 12 point increase-we can reject the youthquake hypothesis using both the combined BES and BSA reported turnout data ( $\mathrm{p}=$ $0.0466)$ and the BES validated vote data $(\mathrm{p}=0.0124)$. In other words, whilst we cannot be exactly sure about the level of turnout change amongst young voters between 2015 and 2017, by conventional statistical standards, we can say that it did not increase by the amount

\footnotetext{
11 More specifically, we specify priors for the VEP turnout model as normal distributions (on the log odds scale) with means of .622 for the intercept (2015 turnout) and 0.142 for the increase in turnout in 2017. For VAP turnout the equivalent numbers are 0.424 and 0.097 . When transformed into probabilities, these coefficients give our estimates of overall VEP and VEP turnout for each election. Because our measures of VEP and VAP turnout are still estimates, we allow for a small amount of uncertainty, giving the distribution of each prior a standard deviation of 0.02 . The standard deviations of the distributions of subgroup means are also given priors (hyperparameters). We use weakly informative (regularizing) priors using folded t-distributions $(\mathrm{df}=3$ ) with a mean of zero and scale parameter of 10 .
}

claimed by those who say there was a youthquake.

If we turn to the Bayesian analysis, the most striking feature is the relatively small credible intervals compared to the conventional confidence intervals. Pooling across age groups and elections increases the precision of our estimates, as does correctly accounting for the fact that we know the change in overall turnout between elections. Using the pooled BES and BSA reported turnout data, the $95 \%$ credible interval for the change in turnout between 2015 and 2017 for 18-24 year olds is between 1.2 and 6.3 points (with a median estimate of 3.6). The $95 \%$ credible interval for the validated vote data is considerably wider-between -8.5 and 6.6 points, with a median of $1.3 .{ }^{12}$ Using the Bayesian approach gives us more confidence that turnout amongst young people did increase in 2017, but it also suggests that it increased by levels similar to the overall increase in turnout as a whole-in other words, it gives us even more confidence that there was not a turnout 'youthquake'.

\subsection{The impact of subjective priors on estimates of turnout change}

Some advocates of the 2017 youthquake may still be sceptical of our results. How much weight should people with strong prior beliefs about a youthquake put on our data? The Bayesian approach to statistics allows for a principled and transparent approach to incorporating subjective beliefs into statistical estimates. In order to do so, however, we need to transform those beliefs into statistical distributions.

There have been three specific claims about the size of a youthquake level increase in turnout amongst (eligible) young people-12 points, 16 points, and 19 points. Three data points is too small to draw a full distribution, but if we assume the shape of the distribution is normal, we can make reasonable assumptions about what it might look like. If there were a normal distribution of estimates, we would expect random draws from this distribution to be one standard deviation away from the mean of the distribution on average. The highest (19) and lowest (12) claims are similarly far apart from the third claim (16). A straightforward approach, then, is to specify a prior where the two extremes are each one standard deviation away from a mean. We adopt this approach and specify a youthquake prior as a normal distribution with a mean of 15.5 and a standard deviation of 3.5.

As is hopefully clear from our earlier examination of these claims, we do not actually believe this is a reasonable prior. What would a more reasonable prior look like? Without any further information about the relationship between age and changes in turnout, our first guess would probably be that the overall level of turnout change applied equally across different age groups. The law of dispersion (Tingsten, 1937), however, implies that when turnout rises we might expect a slightly larger increase in turnout among lower turnout groups because those groups contain a larger number of potential new voters to be mobilised (Persson et al., 2013). We can, then, take an alternative 'modest increase' prior, which is consistent with the Labour party's analysis of a 6.6 point change, and Sturgis and Jennings's 9 point change. If we follow the same logic as above and treat the overall (VEP) change in turnout (3 points) as being one standard deviation below the mean of our distribution, and the higher of the two plausible claims as being one standard deviation above the mean, we get a normal distribution with a mean of 6 points and a standard deviation of 3 .

We examine the effects of these priors using linear probability models on the 18-24 year olds in each dataset. ${ }^{13}$ Furthermore, in order to make clear what the effect of these prior distributions is, we specify a

\footnotetext{
12 The equivalent numbers for the 18-29 age band using the pooled BES and BSA data are a $95 \%$ credible interval of between 1.1 and 5.7 points, with a median of 3.5. Using the BES validated vote data, the $95 \%$ credible is -3.3 to 9.2, with a median of 3.3 .

${ }^{13}$ We repeat the analysis for 18-29 years in appendix 11 . The results are very similar, and even less favourable to the youthquake argument.
} 


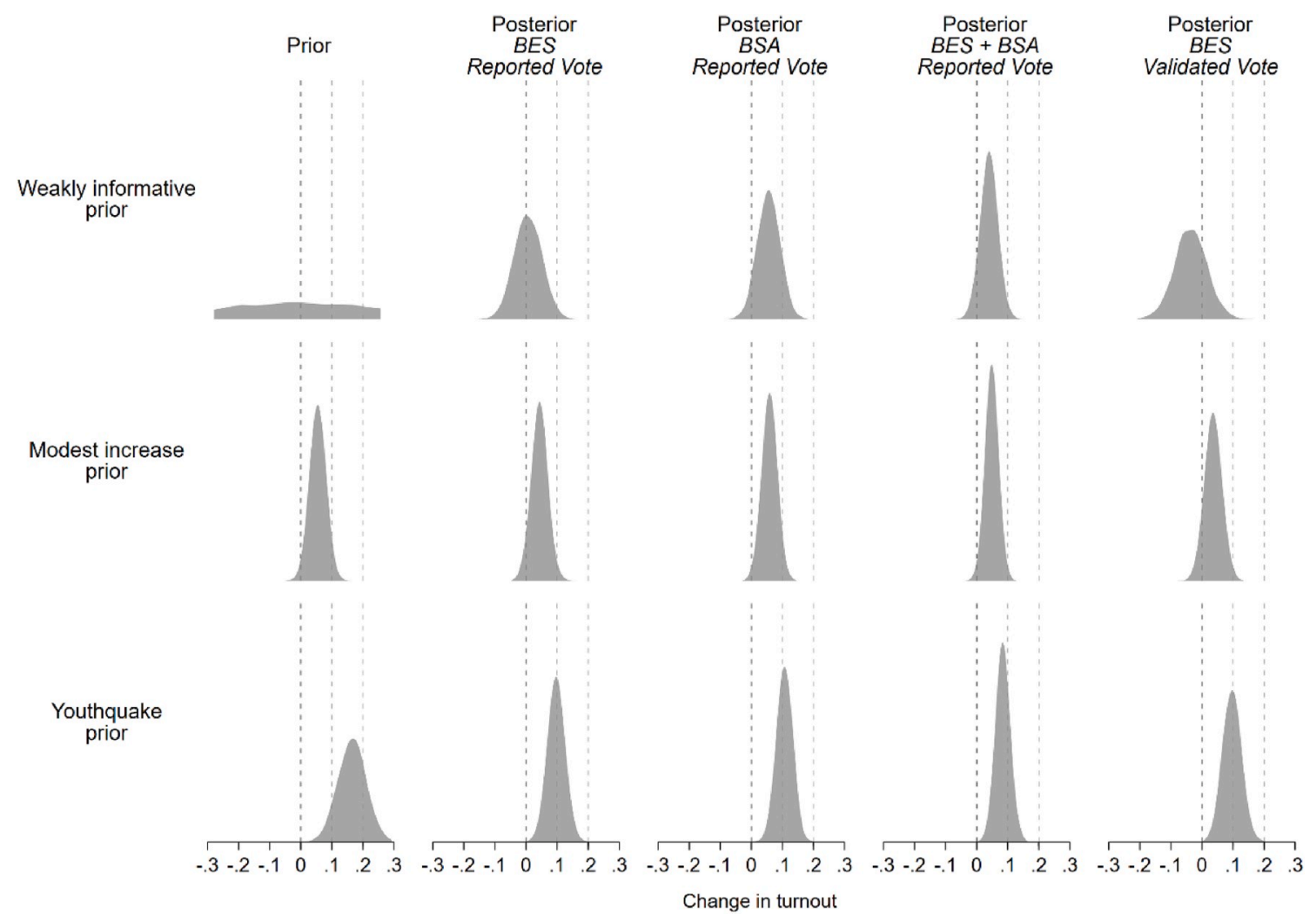

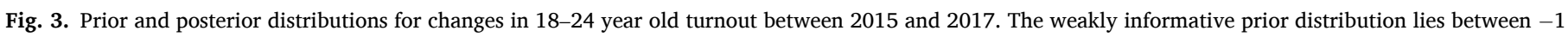
and 1 is truncated here in order to make the other distributions more legible.

weakly informative prior distribution with a mean of 0 and a standard deviation of 30 (which yields a normal distribution in which $99.99 \%$ of the distribution lies between -100 and 100 , the strict mathematical limits by which turnout could change between elections).

Fig. 3 illustrates each of these priors and the resultant posterior distributions from our analysis of the different datasets.

As we would expect, the analysis using the weakly informative prior is very similar to the conventional estimates of turnout change we showed in Fig. 2. If we examine the posterior distributions using our modest increase prior and the pooled BES and BSA data, the $95 \%$ credible interval for the posterior is $0.9-8.8$ points, with a median of 4.9. These numbers are slightly higher but broadly similar to our partially pooled analysis reported in Fig. 2. Using the BES validated vote data, the $95 \%$ credible interval is -1.6 to 8.9 , with a median of 3.6 .

We are primarily interested in how the youthquake prior affects our estimates. The results are clear. Even with a strong prior that there was a large increase in turnout amongst 18-24 years olds in 2017, the BES and BSA data should lead to a substantial downward revision of beliefs about the scale of that change. Although the midpoint of the youthquake prior distribution is ten points higher than the midpoint of our modest increase prior, the median of the posterior distribution using the pooled BES and BSA data with a youthquake prior is 8.5 , just 3.7 higher than the posterior with our modest increase prior. The Bayesian approach allows us to make probabilistic statements about our results. Even with a strong youthquake prior-which we emphasise we do not think is a reasonable prior-the pooled BES and BSA data suggest that there is a $4 \%$ probability that the change in turnout amongst 18-24 years olds was 12 points or higher-the lowest claim made in favour of youthquake. With our modest increase prior, the same data suggest that the probability of a 12 point or higher increase in 18-24 year old turnout is less than $0.00025 \%$.

\section{Conclusions}

It is perhaps unsurprising that following the dramatic and unexpected result of the 2017 election, a similarly dramatic explanation was put forward to explain what happened. As we have shown in this paper, however, we do not have good evidence that the relationship between age and turnout changed dramatically between the 2015 and 2017 elections.

Given this, we need to look elsewhere to account for the rise in Labour's support in the 2017 general election. One such explanation points to the importance of Brexit over the two year period between 2015 and 2017, and the importance of leaders to the short campaign in 2017 (Mellon et al., 2018), and also the degree to which the Brexit referendum caused a potential realignment of electoral choice on the basis of Brexit and liberal-authoritarian values, which are strongly related to age and education (Fieldhouse et al., 2019).

The idea of a 'youthquake' may not tell us much about turnout at the 2017 election. It does reveal, however, the perils of making inferences about electoral turnout and political behaviour more generally. Analysing political behaviour is hard. We have shown here that aggregate level analysis of turnout can easily be misleading and that individual data is necessary. Analysing turnout in surveys is fraught with difficulties. We have detailed our approach to dealing with the problems due to non-response bias and turnout misreporting. We also set out a number of ways in which we can analyse the data, drawing on different statistical traditions, and incorporating different assumptions and priors about what turnout change might look like. All of our analyses concur: there is no evidence of a dramatic change in the relationship between age and turnout between the 2015 and 2017 elections.

\section{Acknowledgment}

This research was conducted under the auspices of the British 
Election Study (BES), which is funded by the Economic and Social Research Council (ESRC): ES/K005294/1.

\section{Appendix A. Supplementary data}

Appendices to this article can be found online at https://doi.org/10 .1016/j.electstud.2020.102129.

\section{References}

Britton, Luke Morgan, 2017. Here's the NME Exit Poll of How Young People Voted in 2017 General Election. NME, 2017. http://www.nme.com/news/nme-exit-poll-you ng-voters-2017-general-election-2086012.

Bürkner, Paul-Christian, 2017. "Brms: an $R$ package for bayesian multilevel models using stan. J. Stat. Software 80 (1). https://doi.org/10.18637/jss.v080.i01.

Cowley, Philip, Kavanagh, Dennis, 2018. The British General Election of 2017. Palgrave Macmillan.

Cutts, D., Fieldhouse, Edward, John, Peter, 2009. Is voting habit forming? The longitudinal impact of a GOTV campaign in the UK. J. Elections, Public Opin. Parties 19 (3). https://doi.org/10.1080/17457280903073914.

Dahir, Ikran, 2017. "We Don't Actually Know How Many Young People Voted in the General Election yet. Buzzfeed, 2017. https://www.buzzfeed.com/ikrd/we-dont-a ctually-know-how-many-young-people-turned-out-to.

Dahlgaard, Jens Olav, Jonas Hedegaard, Hansen, Hansen, Kasper M., Yosef, Bhatti, 2019. Bias in Self-Reported Voting and How it Distorts Turnout Models: Disentangling Nonresponse Bias and Overreporting Among Danish Voters, pp. 1-9. https://doi org/10.1017/pan.2019.9. Political Analysis, March.

Ehsan, Rakib, James, Sloam, Matt, Henn, 2017. Youthquake was real - here's how we know it was more than a myth. The Conversation 31, 2017. January. https://theco nversation.com/youthquake-was-real-heres-how-we-know-it-was-more-than-a-m yth-90970.

Fan, Jianqing, Gijbels, Irène, 1996. Local Polynomial Modelling and its Applications. Local Polynomial Modelling and its Applications. Chapman \& Hall/CRC, Boca Raton https://doi.org/10.1201/9780203748725.

Fieldhouse, Edward, Green, Jane, Evans, Geoffrey, Mellon, Jonathan, Prosser, Christopher, Schmitt, Hermann, van der Eijk, Cees, 2019. Electoral Shocks: the Volatile Voter in a Turbulent World. Oxford University Press.

Fieldhouse, Edward, Green, Jane, Evans, Geoffrey, Schmitt, Hermann, van der Eijk, Cees, Mellon, Jonathan, Prosser, Christopher, 2015. British Election Study 2015 Face-ToFace Post-Election Survey. https://doi.org/10.5255/UKDA-SN-7972-1.

Fieldhouse, Edward, Green, Jane, Evans, Geoffrey, Schmitt, Hermann, van der Eijk, Cees, Mellon, Jonathan, Prosser, Christopher, 2017. British Election Study 2017 Face-toFace Post-Election Survey.

Fieldhouse, Edward, Tranmer, Mark, Russell, Andrew, 2007. Something about young people or something about elections? Electoral participation of young people in Europe: evidence from a multilevel analysis of the European social survey. Eur. J. Polit. Res. 46 (6) https://doi.org/10.1111/j.1475-6765.2007.00713.x.

Gelman, Andrew, Carlin, John, 2014. Beyond power calculations. Perspect. Psychol. Sci. 9 (6), 641-651. https://doi.org/10.1177/1745691614551642.

Greenwald, Anthony, G., Carnot, C.G., Beach, R., Young, Barbara, 1987. Increasing voting behavior by asking people if they expect to vote. J. Appl. Psychol. 72 (2), 315-318. https://doi.org/10.1037/0021-9010.72.2.315.
Heath, Oliver, Goodwin, Matthew, 2017. The 2017 general election, Brexit and the return to two-party politics: an aggregate-level analysis of the result. Polit. Q. 88 (3), 345-358. https://doi.org/10.1111/1467-923X.12405.

Ipsos MORI, 2017. How Britain Voted in the 2017 Election, 2017. https://www.ipsos. com/ipsos-mori/en-uk/how-britain-voted-2017-election.

Mellon, Jonathan, Evans, Geoffrey, Fieldhouse, Edward, Green, Jane, Prosser, Christopher, 2018. Brexit or Corbyn? Campaign and inter-election vote switching in the 2017 UK general election. Parliam. Aff. 71 (4), 719-737. https ://papers.ssrn.com/sol3/papers.cfm?abstract_id=3073203.

Mellon, Jonathan, Prosser, Christopher, 2017. Missing nonvoters and misweighted samples: explaining the 2015 great British polling miss. Publ. Opin. Q. 81 (3), 661-687. https://doi.org/10.2139/ssrn.2631165.

Milbrath, Lester W., 1965. Political Participation: How and Why Do People Get Involved in Politics? Rand McNally, Chicago.

NatCen Social Research, 2017. British Social Attitudes Survey, 2015 [Data Collection]. UK Data Service. https://doi.org/10.5255/UKDA-SN-8116-3. SN: 8116.

NatCen Social Research, 2019. British Social Attitudes Survey, 2017. [Data Collection]. UK Data Service. https://doi.org/10.5255/UKDA-SN-8450-1. SN: 8450.

Persson, Mikael, Solevid, Maria, Öhrvall, Richard, 2013. Voter turnout and political equality: testing the 'law of dispersion' in a Swedish natural experiment. Politics 33 (3), 172-184. https://doi.org/10.1111/1467-9256.12012.

Prosser, Christopher, 2018. The Strange Death of Multi-Party Britain: the UK General Election of 2017. West European Politics.

Robinson, W.S., 1950. Ecological correlations and the behavior of individuals. Am. Socio. Rev. 15 (3), 351. https://doi.org/10.2307/2087176.

Sloam, James, Ehsan, Muhammad Rakib, 2017. Youth Quake: Young People and the 2017 General Election. http://www.if.org.uk/wp-content/uploads/2017/11/Youth -Quake_Final.pdf.

Stan Development Team, 2018. Stan: A C ++ Library for Probability and Sampling, Version 2.16.0. http://mc-stan.org/.

Strate, John M., Parrish, Charles J., Elder, Charles D., Ford, Coit, 1989. Life span civic development and voting participation. Am. Polit. Sci. Rev. 83 (2), 443-464. https:// doi.org/10.2307/1962399.

Sturgis, Patrick, Allum, Nick, Brunton-Smith, Ian, 2009. Attitudes over time: the psychology of panel conditioning. In: Lynn, Peter (Ed.), Methodology of Longitudinal Surveys. John Wiley \& Sons, Ltd, pp. 113-126. https://doi.org/10.1002/ 9780470743874.ch7.

Sturgis, Patrick, Jennings, Will, 2019. "Was there a 'youthquake' in the 2017 general election? Elect. Stud. https://doi.org/10.1016/j.electstud.2019.102065, 2019.

Sturgis, Patrick, Kuha, Jouni, Baker, Nick, Callegaro, Mario, Fisher, Stephen, Green, Jane, Jennings, Will, Lauderdale, Benjamin E., Smith, Patten, 2017. An assessment of the causes of the errors in the 2015 UK general election opinion polls. J. Roy. Stat. Soc. https://doi.org/10.1111/rssa.12329. October.

Tingsten, H., 1937. Political Behavior: Studies in Election Statistics.

University of Essex. Institute for Social and Economic Research, NatCen Social Research, and Kantar Public, 2017. Understanding Society: Waves 1-7, 2009-2016 and Harmonised BHPS: Waves 1-18, 1991-2009. [Data Collection], ninth ed. UK Data Service, SN. 6614.

Verba, Sidney, Lehman Schlozman, Kay, Brady, Henry E., 1995. Voice and Equality : Civic Voluntarism in American Politics. Harvard University Press, Cambridge, Mass ; London.

Whiteley, Paul, Clarke, Harold D., 2017. Understanding Labour's 'Youthquake. The Conversation. 2017. https://theconversation.com/understanding-labours-youthqu ake-80333. 